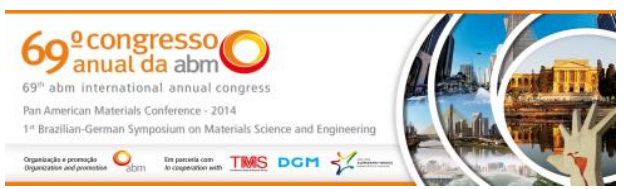

Tema: Corrosão

\title{
INFLUÊNCIA DA MICROESTRUTURA SOBRE A RESISTÊNCIA À CORROSÃO DE UM AÇO MICROLIGADO*
}

\author{
Duberney Hincapie-Ladino ${ }^{1}$ \\ José Wilmar Calderón-Hernández ${ }^{1}$ \\ Guilherme Akio Shimizu² \\ Neusa Alonso-Falleiros ${ }^{3}$
}

\section{Resumo}

No presente trabalho analisou-se a influência de diferentes microestruturas obtidas através de tratamentos térmicos, sobre a resistência à corrosão de um aço microligado, na solução A segundo a norma NACE TM0284-11. Foi utilizada chapa de um aço destinado à conformação de tubo API $5 \mathrm{~L}$ X65 para confeccionar as amostras. Algumas destas foram submetidas a tratamentos térmicos (Temperado, Temperado seguido de revenimento, esferoidização) e o restante foi utilizado tal como recebido. Os materiais foram submetidos a ensaios de polarização linear, num eletrólito composto por $0,5 \%$ ácido acético e $5 \%$ cloreto de sódio (solução A, NACE TM0284-11) fazendo-se purga com $\mathrm{N}_{2}$ e injeções de $\mathrm{H}_{2} \mathrm{~S}$. Foram realizados exames em microscópio óptico. Os valores de resistência de polarização mostraram que a ordem decrescente de resistência à corrosão de acordo com o tratamento térmico foi: (Esferoidizada) > (Tal Como Recebido) > (Temperada, Temperada e Revenida). Tal fato pode ser explicado pela quantidade de interfaces presentes em cada microestrutura (cementita globulizada em matriz ferrítica; ferrita com perlita; martensita e martensita revenida), sendo que quanto menor a área de interfaces, maior o valor para resistência à corrosão.

Palavras-chave: Aço microligado; Sulfeto de hidrogênio; Resistência de polarização; Velocidade de corrosão.

\section{INFLUENCE OF MICROSTRUCTURE ON CORROSION RESISTANCE OF MICROALLOYED STEEL}

\section{Abstract}

It was the aim of this study to analyze the influence of different microstructures obtained by heat treatment on the corrosion resistance of microalloyed steel in the solution A according to NACE TM 0284-11 standard. A steel plate used to fabricate pipeline API 5L X65 was used. Some of them were heat treated (water-quenched, quenched and tempered and spheroidized) other tested in the as received condition. The test specimens were evaluated by Linear Polarization in an electrolyte consisting of $5 \%$ sodium chloride and $0.5 \%$ acetic acid (Solution A according to NACE TM0284-11 standard) purging with nitrogen and $\mathrm{H}_{2} \mathrm{~S}$ gas injection. The materials were submitted to optical microscope exams $(\mathrm{OM})$ to characterize the microstructure. The polarization resistance values showed in descending order regarding corrosion resistance according to the heat treatment: spheroidized $>$ as-received $>$ waterquenched, quenched and tempered. This can be explained by the amount of interface present in each microstructure (spheroidized cementite in ferritic matrix, ferrite-pearlite, martensite and tempered martensite), so lower interface leads to high corrosion resistance.

Keywords: Microalloyed steel; Hydrogen Sulfide; Polarization resistance, Corrosion rate.

1 Engenheiro Mecânico, Doutorando do Programa de Engenharia Metalúrgica e de Materiais, Escola Politécnica, USP, São Paulo, SP, Brasil.

2 Engenheiro metalúrgico e de materiais, Departamento de Engenharia Metalúrgica e de Materiais, Escola Politécnica, USP, São Paulo, SP, Brasil.

3 Engenheira Metalurgista, doutora, Docente do Departamento de Engenharia Metalúrgica e de Materiais, Escola Politécnica, USP, São Paulo, SP, Brasil.

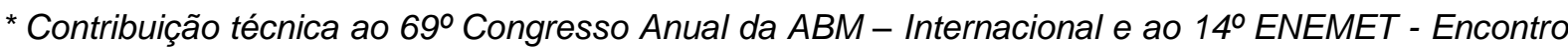
Nacional de Estudantes de Engenharia Metalúrgica, de Materiais e de Minas,21 a 25 de julho de 2014, São Paulo, SP, Brasil.
} 


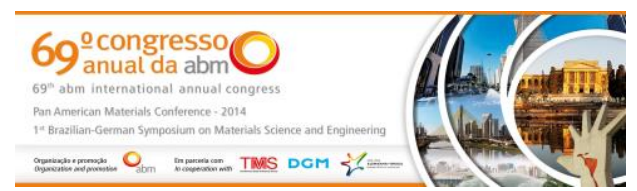

\section{INTRODUÇÃO}

Com o aumento do consumo mundial de combustíveis fósseis, surgiu também a demanda por materiais de melhor qualidade para extraí-los e transportá-los. Contudo, o ambiente em que ocorre a extração e o transporte geralmente é altamente corrosivo, por isso devem ser empregados aços com melhores propriedades [1]. Para transportar óleo e gás natural são utilizados os aços Alta Resistência e Baixa Liga (ARBL), este tipo é escolhido porque são aços que possuem uma boa resistência e uma boa tenacidade a baixas temperaturas, sendo assim, o tubo feito de aço ARBL pode transportar fluidos com pressões elevadas. Um exemplo disso foi a construção do Gasoduto Brasil-Bolívia. No Trecho Norte do gasoduto o material escolhido foi o API 5L X70 com diâmetro nominal de 32" e extensão no lado boliviano de $557 \mathrm{~km}$ e do lado brasileiro 1264 km; no Trecho Sul foram utilizados tubos API 5L X65 e API 5L X70, com diâmetros 24", 20", 18" e 16", com extensão total de $1190 \mathrm{~km}$; no trecho de interligação foi utilizado tubo API 5L X65 com diâmetro DN 24" com uma extensão de 153 km [2]. Qualquer falha que ocorra num duto que transporta petróleo e/ou derivados pode causar sérios problemas ambientais, além da perda econômica.

Quando os aços microligados são corroídos em meio aquoso e, na presença de ácido sulfídrico $\left(\mathrm{H}_{2} \mathrm{~S}\right)$ pode ocorrer fratura induzida por hidrogênio (Hydrogen Induced Cracking-HIC) ou perda das propriedades mecânicas provocada pela entrada de hidrogênio no metal [3]. Este fenômeno se inicia com a corrosão do aço no meio aquoso onde são gerados átomos de hidrogênio, os quais na presença de $\mathrm{H}_{2} \mathrm{~S}$ parte do hidrogênio atômico formado, na superfície do aço, difunde-se até atingirem sítios preferenciais de aprisionamento, onde forma-se hidrogênio molecular, gerando um campo de tensões ao seu redor, podendo causar a nucleação e propagação de trincas [3]. A microestrutura dos aços microligados em meios contendo $\mathrm{H}_{2} \mathrm{~S}$ apresenta diferenças na velocidade de corrosão, e consequentemente uma diferença no teor de hidrogênio na superfície do aço. Segundo Her-hsiung et. al. 1996 [4] quanto maior a fração volumétrica de ferrita de Widmanstätten, maior a resistência à corrosão. Microestruturas de ferrita e ferrita acicular também apresentam bom desempenho quanto a resistência à corrosão tanto na solução A como na solução B da norma NACE TM 0284-11 [5,6]. Por outro lado, microestruturas de perlita e martensita apresentam menor resistência à corrosão [5-7]. Percebe-se que a relação entre microestrutura dos aços alta resistência baixa liga e sua resistência à corrosão em meio contendo sulfeto, não está esclarecida completamente. Isso justifica a presente pesquisa.

\section{MATERIAIS E MÉTODOS}

No presente trabalho foram utilizadas amostras de chapa de um aço destinado à conformação de tubo API 5L X65, com espessura de $18 \mathrm{~mm}$. A composição química da placa utilizada é mostrada na Tabela 1.

Tabela 1. Composição química da placa de aço utilizada. Valores em porcentagem em massa

\begin{tabular}{cccccccccccc}
\hline $\mathrm{C}$ & $\mathrm{Mn}$ & $\mathrm{P}$ & $\mathrm{S}$ & $\mathrm{Si}$ & $\mathrm{Ni}$ & $\mathrm{Cr}$ & $\mathrm{Al}$ & $\mathrm{Cu}$ & $\mathrm{V}$ & $\mathrm{Nb}$ & $\mathrm{Ti}$ \\
\hline 0,100 & 1,510 & 0,019 & 0,001 & 0,230 & 0,015 & 0,020 & 0,044 & 0,010 & 0,050 & 0,050 & 0,016 \\
\hline
\end{tabular}

O eletrólito utilizado nos ensaios eletroquímicos foi à solução $A$ da norma NACE TM0284-11 [8], composta de 5\% cloreto de sódio e 0,5\% ácido acético em água

* Contribuição técnica ao 69 Congresso Anual da ABM - Internacional e ao 14ํㅡㄹ ENEMET - Encontro Nacional de Estudantes de Engenharia Metalúrgica, de Materiais e de Minas,21 a 25 de julho de 2014, São Paulo, SP, Brasil. 


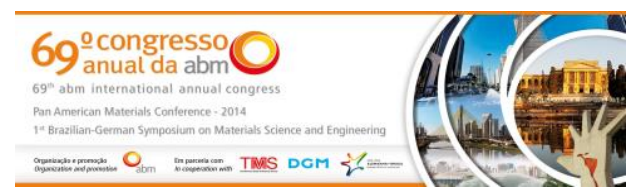

destilada e deionizada. As amostras foram submetidas a ensaios de Polarização Linear para determinação da Resistência de Polarização (Rp).

\subsection{Tratamentos Térmicos e Exames Micrográficos}

Os tratamentos térmicos realizados estão apresentados na Tabela 2. Estes foram realizados em um forno tubular a vácuo disponível no Departamento de Metalurgia e Materiais da Escola Politécnica da USP, para evitar possível descarbonetação do aço.

Tabela 2. Tratamentos térmicos realizados antes dos ensaios eletroquímicos.

\begin{tabular}{|c|c|c|c|c|c|}
\hline & $\begin{array}{c}\text { Tempo de } \\
\text { Homogeneização } \\
(\text { min) }\end{array}$ & $\begin{array}{c}\text { Temp. de } \\
\text { Revenimento } \\
\left({ }^{\circ} \mathrm{C}\right)\end{array}$ & $\begin{array}{c}\text { Tempo de } \\
\text { Revenimento } \\
(\min )\end{array}$ & $\begin{array}{c}\text { Temp de } \\
\text { Esferoidização } \\
\left({ }^{\circ} \mathrm{C}\right)\end{array}$ & $\begin{array}{c}\text { Tempo de } \\
\text { Esferoidização } \\
(\mathrm{min})\end{array}$ \\
\hline TCR & - & - & - & - & - \\
\hline T & 20 & - & - & - & - \\
\hline TR & 20 & 600 & 60 & - & - \\
\hline E & 20 & - & - & 600 & 720 \\
\hline
\end{tabular}

TCR: Tal como Recebido; T: Temperado-água; TR: Temperado-água e Revenido; E: Esferoidizado, Temperatura de Austenitização $\left({ }^{\circ} \mathrm{C}\right)$.

Após os tratamentos térmicos foram retiradas amostras, expondo a superfície perpendicular ao sentido de laminação da chapa, correspondentes a cada tratamento térmico, elas foram embutidas em baquelite, lixadas e polidas até pasta de diamante $1 \mu \mathrm{m}$. Após serem polidas, utilizou-se o reagente Nital $2 \%$, foram feitas imagens de microscópio ótico (MO) para verificar as microestruturas obtidas após tratamentos térmicos.

\subsection{Polarização Linear - Resistência de Polarização}

Os corpos-de-prova utilizados nos ensaios eletroquímicos foram cortados lixados e embutidos em baquelite expondo a seção perpendicular ao sentido de laminação, com uma área aproximada de $1 \mathrm{~cm}^{2}$. Os corpos-de-prova foram lixados até lixa 600, lavados e secos com álcool etílico e jato de ar.

Foi utilizado um eletrólito composto por $5 \% \mathrm{NaCl}$ (cloreto de sódio) e 0,5\% $\mathrm{CH}_{3} \mathrm{COOH}$ (ácido acético) em água destilada, correspondente à solução $\mathrm{A}$ da norma NACE TM0284-11. A solução $A$ foi desaerada borbulhando gás nitrogênio no tempo mínimo de uma hora com vazão superior a 200 mililitros por minuto para cada litro de eletrólito, como recomenda a norma NACE TM0284-11 [8]. Após desaeração, a solução é transferida até a célula eletroquímica do tipo balão volumétrico, onde o corpo de prova fica submerso num volume de aproximadamente $700 \mathrm{~mL}$ de solução. Após realiza-se uma nova desaeração por mais 30 minutos, completado este tempo, o fornecimento de nitrogênio é cortado e inicia-se a injeção de $\mathrm{H}_{2} \mathrm{~S}$ com vazão superior a 100 mililitros por minuto por litro de eletrólito por 1 hora. Nos ensaios foi utilizado contra-eletrodo de platina e eletrodo de calomelano saturado (ECS) como referência.

O método para avaliar a resistência à corrosão utilizado foi a Polarização Linear para se medir a Resistência de Polarização (Rp). Nesse método são obtidos dados de densidade de corrente em potenciais próximos do potencial de corrosão $( \pm 20 \mathrm{mV})$. A

\footnotetext{
* Contribuição técnica ao 69ำ Congresso Anual da ABM - Internacional e ao 14ํㅡㄹ ENEMET - Encontro Nacional de Estudantes de Engenharia Metalúrgica, de Materiais e de Minas,21 a 25 de julho de 2014, São Paulo, SP, Brasil.
} 


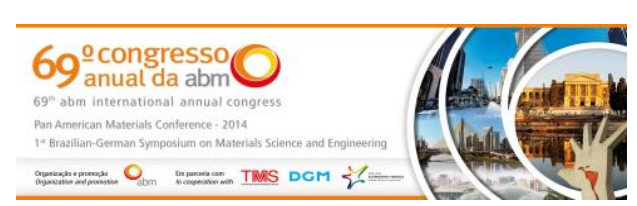

Rp corresponde à tangente à curva de polarização quando a sobretensão tem valor nulo. Os ensaios foram feitos iniciando numa sobretensão de $-20 \mathrm{mV}$, utilizando velocidade de varredura de $1 \mathrm{mV} / \mathrm{s}$, até uma sobretensão de $20 \mathrm{mV}$. Foram tomadas 6 medidas a cada 10 minutos para se obter 6 valores de Rp para cada amostra por ensaio e foram feitos 3 ensaios para cada tipo de microestrutura. Os ensaios foram realizados a temperatura de $(25 \pm 2)^{\circ} \mathrm{C}$, de acordo com a norma NACE TM0284-11.

\section{RESULTADOS E DISCUSSÃO}

As amostras foram polidas e atacadas com reagente Nital $2 \% \mathrm{com}$ a finalidade de observar as microestruturas antes e após os tratamentos térmicos. Na Figura 1, temos que o material tal como recebido (TCR) apresenta uma microestrutura bandeada constituída de ferrita (fase clara) e perlita (região escura).

Após tratamento de têmpera verifica-se que é formada uma microestrutura martensítica, que pode ser visualizada na Figura 2.

A Figura 3 apresenta a microestrutura após o Revenimento, o qual pouco alterou a estrutura martensítica observada no microscópio óptico.

A Figura 4 apresenta o resultado do tratamento realizado com objetivo de esferoidizar a cementita. Pode-se verificar um esboroamento da perlita, dividindo-a em pequenas esferas, resultado de um tratamento a $600^{\circ} \mathrm{C}$ por $12 \mathrm{~h}$.

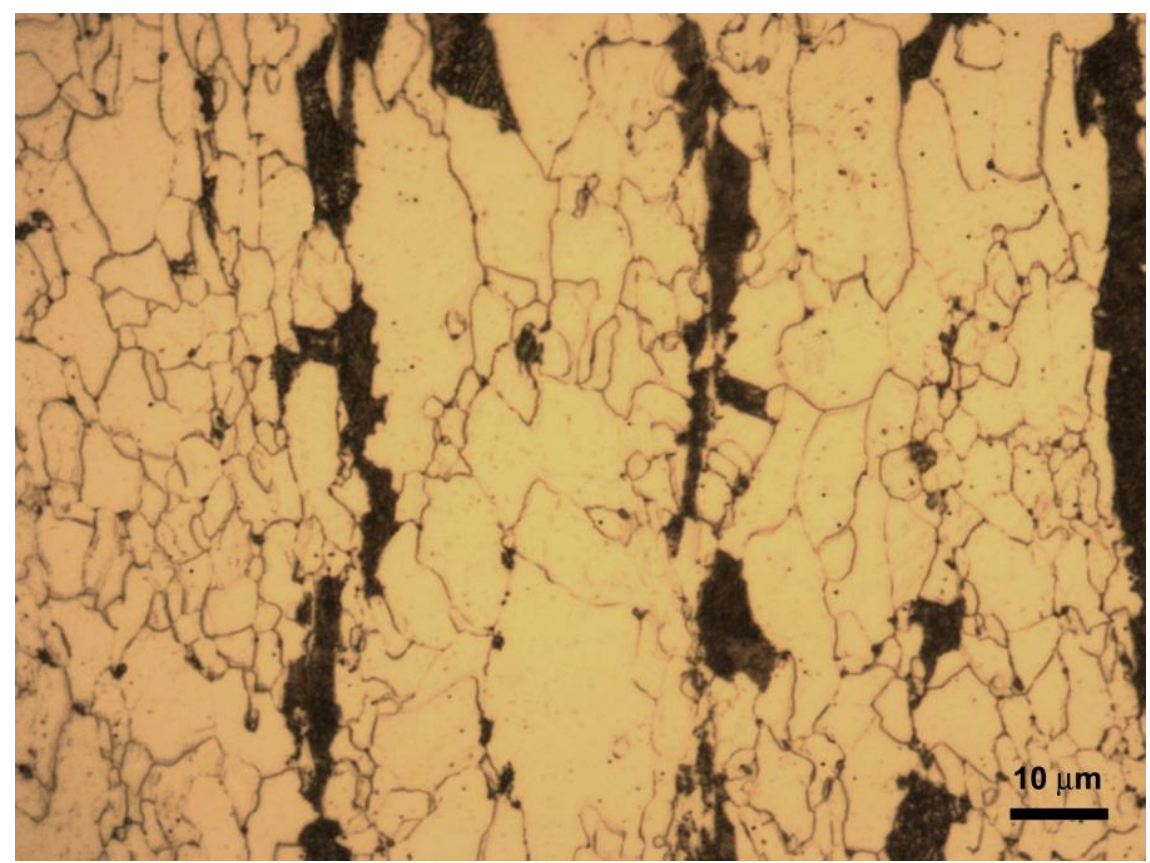

Figura 1. Aço microligado no estado Tal Como Recebido (TCR) Nota-se estrutura bandeada de ferrita e perlita. Nital $2 \%$, MO. Aumento de 500X.

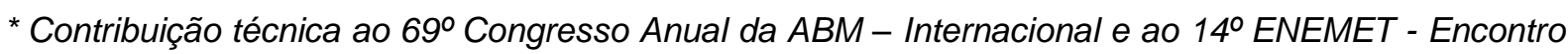
Nacional de Estudantes de Engenharia Metalúrgica, de Materiais e de Minas,21 a 25 de julho de 2014, São Paulo, SP, Brasil.
} 


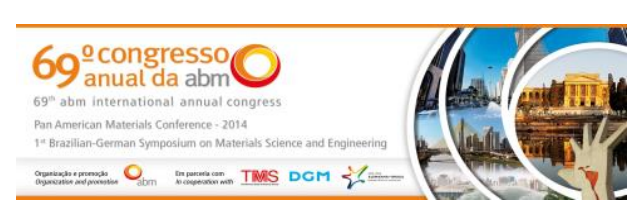

\subsection{Medida da Resistência de Polarização}

Para se medir a resistência de polarização $(R p)$ foi utilizado o método da polarização linear. Tal parâmetro é obtido através do monitoramento da densidade de corrente (I) em função do potencial de eletrodo aplicado (E) [9]. A resistência de polarização é inversamente proporcional à velocidade de corrosão, ou seja, quanto mais rápido o metal corroer, menor será o valor da Rp. O valor de Rp é o valor da tangente à curva $E$ versus $i$, no ponto de sobretensão nula, que no ensaio de polarização linear é obtido através da tangente ao trecho linear, passando pelo potencial de corrosão (sobretensão nula) [9]. Tais medidas foram realizadas para comparar a resistência à corrosão do mesmo material (placa de aço microligado destinada à confecção de tubo API 5L X65) com tratamentos térmicos distintos, num mesmo eletrólito, o qual foi a Solução A da NACE TM0284-11.

Os valores de Rp de todas as amostras em função do tempo de imersão estão representados na Figura 5. Nota-se que os valores de Rp são praticamente constantes ao longo do tempo.

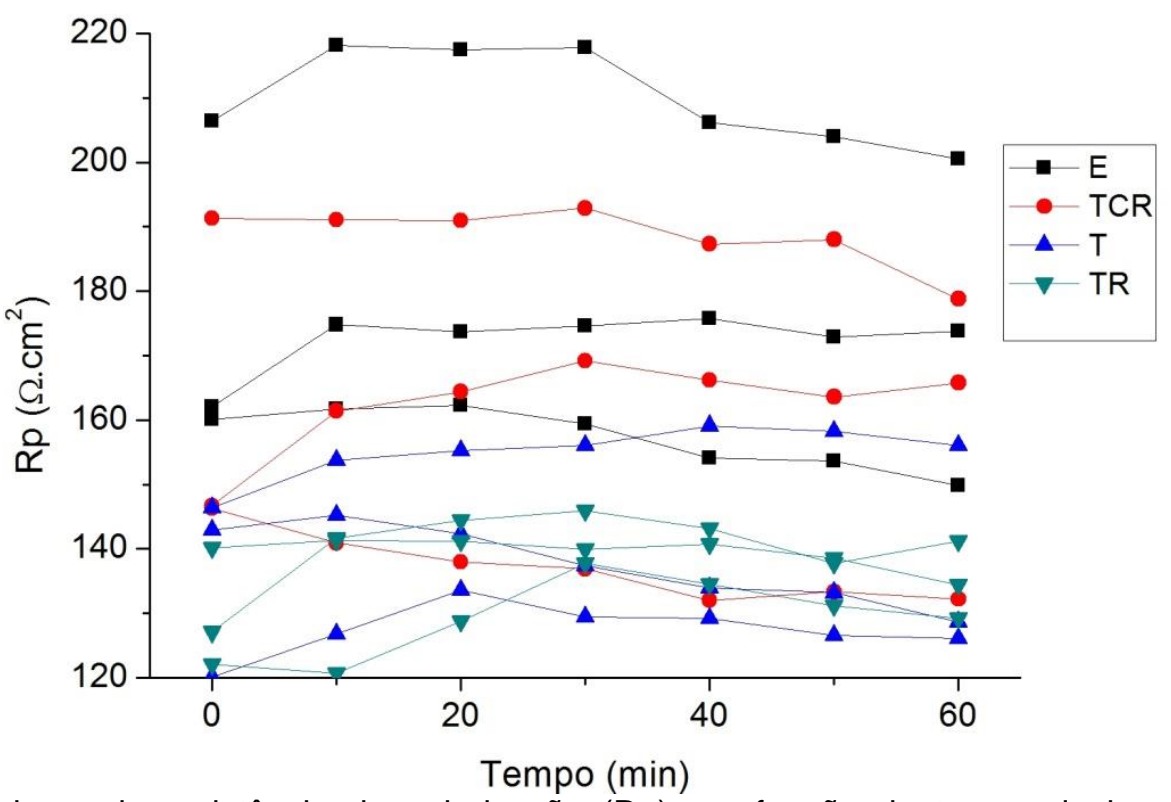

Figura 5. Valores de resistência de polarização (Rp) em função do tempo de imersão para os tratamentos térmicos realizados.

No entanto, observa-se, principalmente para as condições E e TCR que as três réplicas realizadas mostram valores de $\mathrm{Rp}$ num intervalo relativamente grande, quando comparadas com aquelas realizadas para as condições T e TR. Além disso, observa-se que os menores valores de Rp foram obtidos para as condições T e TR. Estas observações ficam mais evidentes quando se examina o gráfico da Figura 6.

\footnotetext{
* Contribuição técnica ao 69ำ Congresso Anual da ABM - Internacional e ao 14ํㅡㄹ ENEMET - Encontro Nacional de Estudantes de Engenharia Metalúrgica, de Materiais e de Minas,21 a 25 de julho de 2014, São Paulo, SP, Brasil.
} 

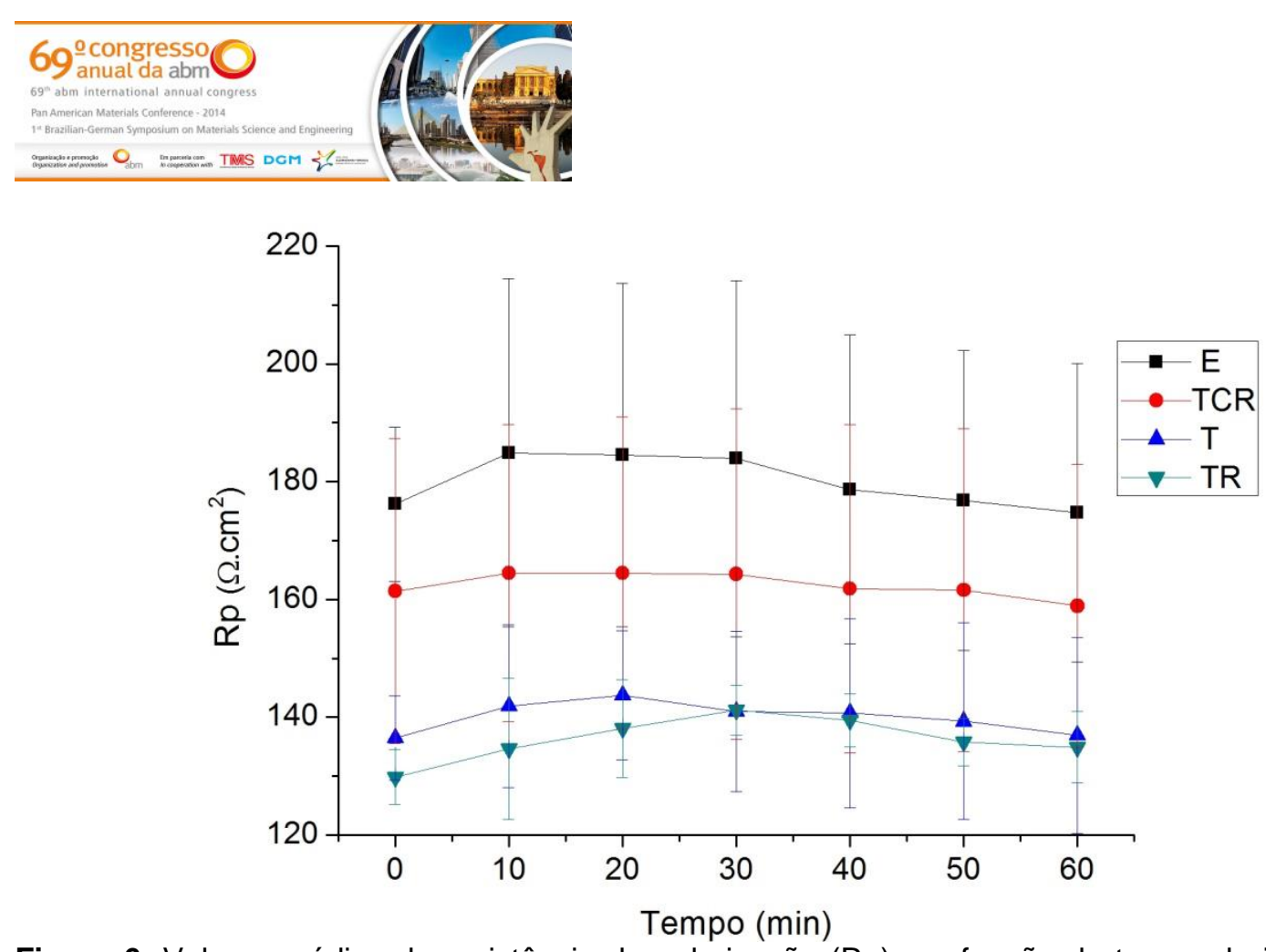

Figura 6. Valores médios de resistência de polarização $(R p)$ em função do tempo de imersão para diferentes tratamentos térmicos. (E: Resistência de polarização média das amostras Esferoidizadas; TCR: Resistência de polarização média das amostras Tal Como Recebidas; T: Resistência de polarização média das amostras Temperadas; TR: Resistência de polarização média das amostras Temperadas e Revenidas).

Na Figura 6 são mostradas as curvas das médias de Rp para cada tratamento térmico. Tais curvas foram obtidas fazendo-se a média de Rp para cada tempo de imersão (média de 3 pontos em cada tempo). Verifica-se que a diferença do maior para o menor valor de Rp médio encontrada é de aproximadamente $50 \Omega \mathrm{cm}^{2}$.

É possível observar também que as amostras que sofreram têmpera e as que passaram por têmpera e revenimento apresentam valores de Rp praticamente iguais. As condições de tratamento térmico que tiveram valores de $\mathrm{Rp}$ mais elevados também apresentaram os maiores desvios-padrão.

Em princípio, é esperado que sistemas com maior resistência à corrosão apresentem maiores desvios-padrão em seus valores médios, pois a própria dificuldade do processo corrosivo já é motivo para originar dispersões, uma vez que o material pode ou não corroer naquele instante considerado.

Ainda considerando a Figura 6, nota-se que em média o valor de Rp no momento inicial é um pouco mais baixo e a partir de 20 minutos de imersão os valores são praticamente constantes com o tempo. Isso pode ser explicado pelo fato da área exposta no início ser maior, devido ao acabamento de lixa 600 utilizado e com o tempo ir diminuindo à medida que a corrosão progride. $\mathrm{O}$ processo corrosivo em meio ácido realiza um ataque semelhante a um polimento, eliminando os riscos de lixa.

A Tabela 3 apresenta os resultados de perda de massa médios calculados com todos os valores de $\mathrm{Rp}$ obtidos (18 por cada tratamento térmico) calculados teoricamente a partir dos valores de resistência de polarização, com procedimento apresentado em trabalho anterior [10], a fim de auxiliar a comparação dos desempenhos dos tratamentos térmicos estudados.

\footnotetext{
* Contribuição técnica ao 69ำ Congresso Anual da ABM - Internacional e ao 14ํㅡㄹ ENEMET - Encontro Nacional de Estudantes de Engenharia Metalúrgica, de Materiais e de Minas,21 a 25 de julho de 2014, São Paulo, SP, Brasil.
} 


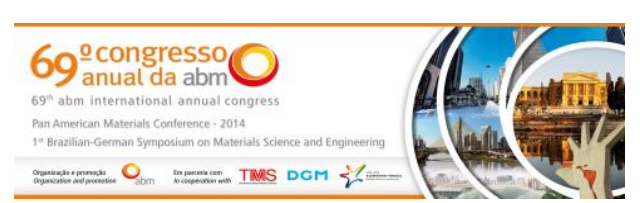

Tabela 3. Resultado de perda de espessura por ano $\left(\mathrm{mm}^{\mathrm{anno}}{ }^{-1}\right)$, calculado segundo norma ASTM G102-89 [11]. Com valores de Icorr obtidos por ajuste das curvas de polarização linear [10]

\begin{tabular}{|l|c|c|}
\hline & \multicolumn{2}{|c|}{ Perda de massa $\left(\mathrm{mm}^{-a n 0^{-1}}\right)$} \\
\hline Esferoidizada & 1,2 & $+/-0,2$ \\
\hline Tal Como Recebida & 1,3 & $+/-0,2$ \\
\hline Temperada & 1,5 & $+/-0,1$ \\
\hline Temperada e Revenida & 1,5 & $+/-0,1$ \\
\hline
\end{tabular}

Sobre a Figura 6 e Tabela 3 nota-se que existe uma sequência de resistência de polarização e perda de massa teórica por tratamento térmico independentemente do tempo de imersão, sendo que a condição $E$ apresenta valores maiores, seguida da condição Tal Como Recebida, Temperada e Temperada e Revenida muito próximas $(E>T C R>(T \& T R))$.

Dois mecanismos podem explicar as diferentes resistências à corrosão: a homogeneização da composição química durante o tratamento térmico e a quantidade de interfaces das microestruturas obtidas em cada caso. O processo de homogeneização pode ser entendido como a melhora da distribuição de elementos dispersos no material. A estrutura do material Tal Como Recebido é uma estrutura bandeada a qual ocorre quando há segregação.

Dado que a temperatura do tratamento térmico é relativamente baixa, é esperada alguma difusão, mas provavelmente em pequena escala. Descartada a possibilidade de que tenha ocorrido homogeneização, outra hipótese para explicar os resultados de resistência à corrosão é a quantidade de interfaces geradas pelos diferentes tratamentos térmicos.

No presente trabalho foram obtidos basicamente três tipos diferentes de microestrutura: ferrítica-perlítica bandeada (material Tal Como Recebido), martensita (tratamento de têmpera, têmpera e revenimento) e parcialmente esferoidizada (tratamento de Esferoidização), pode-se notar pelas imagens (Figuras 1 a 4) que a ordem crescente de quantidade de interfaces por microestrutura é: esferoidizada (Figuras 4), perlítica-ferrítica (Figuras 1) e martensítica (Figura 2 e 3).

O aço que sofreu Esferoidização ficou com menor número de interfaces quando comparado ao material Tal Como Recebido, pois a perlita desmanchou-se em pequenos glóbulos. Porém, os aços que sofreram Têmpera e Têmpera e Revenimento ficaram com maior quantidade de interfaces quando comparados com o material Tal Como Recebido, já que foram formadas muitas agulhas.

Como a corrosão ataca preferencialmente as interfaces da microestrutura, os aços cujas microestruturas têm mais interfaces sofrem mais corrosão. Tal fato pode ser confirmado pelos resultados obtidos para a resistência de polarização, que indicam que em média os valores das resistências à corrosão para aços com menor número de interfaces foram mais elevados (Figuras 5 e 6 )

\section{CONCLUSÃO}

O material Tal Como Recebido apresentava bandeamento visível, com estrutura de ferrita e perlita, enquanto que as outras microestruturas obtidas através de tratamentos térmicos não apresentavam bandeamento, no entanto, é importante ressaltar que a segregação ainda esta presente.

Os valores de resistência de polarização em ordem decrescente foram, de acordo com a microestrutura: Esferoidizada > Tal Como Recebida > (Temperada \& Temperada e Revenida).

* Contribuição técnica ao 69ำ Congresso Anual da ABM - Internacional e ao 14ํㅡㄹ ENEMET - Encontro Nacional de Estudantes de Engenharia Metalúrgica, de Materiais e de Minas,21 a 25 de julho de 2014, São Paulo, SP, Brasil. 


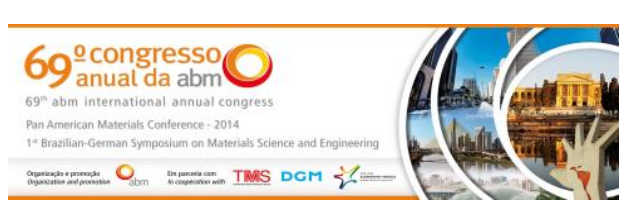

A principal hipótese para explicar esse comportamento é a quantidade de superfície de interfaces, sendo que a ordem de área de interfaces realmente é inversa a ordem de resistência de polarização.

\section{Agradecimentos}

Os autores agradecem à Companhia Brasileira de Metalurgia e Mineração (CBMM) pelo suporte à realização desta pesquisa.

\section{REFERÊNCIAS}

1 Hill RT. Offshore oil and gas development activities and challenges. proceding of microalloyed steels for the oil and gas industry Symposium. In: Proceedings TMS; 2007. p.15-26.

2 Modelagem do gasoduto Bolivia-Brasil. [acesso em 14 Jan. 2014]. Disponível em: http://www2.dbd.puc-rio.br/pergamum/tesesabertas/0612536_08_cap_05.pdf.

3 Sastri VS, Ghali E, Elboujdaini M. Corrosion Prevention and Protection Practical Solutions. Ottawa: John Wiley \& Sons Ltd.; 2007.

4 Her-hsiung huang, Wen-ta tsai, Ju-tung lee. Electrochimica Acta. 1996;41(7-8):1191-99.

5 Hincapie ladino $D$. Resistência à corrosão e ao trincamento induzido por hidrogênio de aços para tubos API 5LX65 [Dissertação de Mestrado]. São Paulo: Departamento de Engenharia Metalúrgica e de Materiais, Escola Politécnica da Universidade de São Paulo; 2012.

6 Hincapié-ladino D, Goldenstein H, Perez de oliveira M, Hernandez JWC, Montagna LS, Falleiros NA. Trincamento de tubos API $5 \mathrm{LX} 65$ e resistência à corrosão em meio contendo $\mathrm{H}_{2} \mathrm{~S}$. In: $67^{\circ}$ Congresso ABM - Internacional; 31 de julho a 3 de agosto de 2012; Rio de Janeiro, Brasil. São Paulo: ABM; 2012.

7 Lucio-garcia MA, Gonzalez-rodriguez JG, Casales M, Martinez L, Chacon-nava JG, Neri-flores MA, Martinez-villafañe A. Corr. Sci. 2009;51(10):2380-86.

8 ANSI/NACE. Standard TM0284-2011: Standard test method for evaluation of pipeline and pressure vessel steels for resistance to hydrogen induced cracking. Nace international Houston; 2003.

9 Wolynec S. Técnicas eletroquímicas em corrosão. São Paulo: Editora da Universidade de São Paulo - EDUSP; 2003.

10 Hincapié-ladino D, Hernandez JWC, Falleiros NA. Determinação da velocidade de corrosão de aço microligado em meio contendo $\mathrm{H}_{2} \mathrm{~S}$. In: 68 Congresso ABM Internacional; 30 de julho a 2 de agosto de 2013; Belo Horizonte, Brasil. São Paulo: ABM; 2013.

11 ASTM. Standard G102-89: Standard practice for calculation of corrosion rates and related information from electrochemical measurement. West Conshohocken; 2010.

\footnotetext{
* Contribuição técnica ao $69^{\circ}$ Congresso Anual da ABM - Internacional e ao 14ํㅡㄹ ENEMET - Encontro Nacional de Estudantes de Engenharia Metalúrgica, de Materiais e de Minas,21 a 25 de julho de 2014, São Paulo, SP, Brasil.
} 